means of an attic syringe or cannula. O wing to the frequency with which they are complicated with caries of the head of the mallens, or of the anterior attic wall, a good deal of what has to be said regarding caries of the ossicles applies to them. When caries of the temporal bone is the cause of the obstinacy of the suppuration some operation is imperative, and delay in such cases is dangerous. It is impossible in this paper to discuss the subjective and objective symptoms of this complication or its operative treatment; suffice it to say that the nature of the discharge, which may be copious and creamy, or thin and bloody, but is always offemsive, together with the changes to be seen in or around the ear, and especially the disturbances which arise when the facial nerve is involved, should lead one to suspect the nature of the case. Caries of the ossicles is a frequent cause of the resistance of chronic suppuration to treatment, and great improvement in our results has appeared since the removal of the ossicles (" ossiculectomy") has become a recognised operation in otology. The operation is undertaken to remove the cause of the discharge or to improve the hearing after the discharge has ceased. It is with the former that we have to do here. When there is a persistence of discharge with a perforation of Shrapnell's membrane, chronic attic trouble is indicated, and, when the anatomical relations of this part of the tympanum are considered, it will be seen that disease there is an hourly menace to life. The chief cause of this persistence is caries of the head of the malleus, or body of the incus, or both, or of the anterior attic wall. Nothing short of removal of the bones in question, and curetting of the bony wall will be of use, and, unless there be indications for opening the antrum, this should certainly be done before proceeding to the more grave mastoid operation. When discharge persists with a perforation in the posterior-superior segment of the membrane, the usual cause is caries of the descending process of the incus, a complication by which the attic may later become secondarily affected. Removal of the malleus, together with the remains of the incus and the membrane is indicated, and in most cases is followed by a rapid improvement. It is when the perforation is in these two situations that ossiculectomy is indicated, the caries which one sees at the tip of the handle of the zaalleus yielding to ordinary treatment.

It only remains to speak npon the treatment of cholesteatomata. There is but one way to deal with them-that is, removal. The method by which this is effected depends upon their position, varying according as they are in the upper or lower part of tympanum or extending into the mastoid process. In the latter саго thes can only be efficiently removed by a mastoid operation. When only in the tympanum, careful loosening and washing out with the intratympanic gyringe may be all that is required, but often one has to remore them under general anæsthesia. When in the attio cholesteatomatous collections are often especially difficult to get away, requiring most careful washing out with a special cannula.

\section{THE UNION OF WOUNDS.}

Mr. Prckering Pick has done good service to gargery in insisting, as he has done in the Bradshaw Lrecture, on the unity of all the various processes by aid of which the union of wounds takes place, and in showing that in all cases what makes wounds unite is inflammation. Obviously the whole question hinges on the definition of inflammation. Briefly and succinctly inflammation may be defined as the "response of living tissue to injury." Given in Mr. Pickering Pick's own words it is " a modification of the normal physiological processes in the various tissues of the body, resulting from the application of some irritant to the part, this process being attended or followed by the formation of a new material of a less highly organised nature than the original tissue in which the inflammation has taken place." The amount and degree of inflammation, then, must depend to large extent upon the degree, and especially on the duration, of the irritation to which the part is exposed, and herein lies the great difference between the mode of union in a septic and an aseptic wound. In the aseptic wound, however severe the injury may be, it is of momentary duration; while in the septic wound the momentary irritation of the injury is followed by a prolonged irritation arising from the growth of septic organisms. Thus the amount and degree of the resulting inflammation, and the character of the resulting tissue differ, but in each case it is inflammation which heals the wound. Of the five classical ways in which wounds are said to unite, $\mathrm{Mr}$. Pick entirely discards the first, namely, that by immediate union, prinary adhesion, or direct growing together of the serered surfaces, maintainingithat there is and must be some connecting material to cause the cut surfaces to stick together, and, in fact, that the difference between this mode and first intention is only one of degree. He then traces out the importance of the part played by inflammation in all the other modes of union, holding that there are but two ways in which wounds unite, namely, without suppuration and with suppuration, and that the difference between these two conditions is very slight, being one of degree rather than of kind, and thatithey are both the result of the same morbid process going on in the part-that is inflammation. This simplifies the matter vastly.

THE STEREOSCOPE.

Dr, Mackenzie Davidson has done well in drawing attention to that far too much neglected instrument, the stereoscope. Everyone knows the difficulty that there of ten is in properly interpreting ordinary photographic illustrations of pathological apreurances. Much, however, that appears meaningless where everything is depicted in the same plane becomes at once instractive as soon as it stands out in the stereoscope, and occupies its true position in regard to its surroundings. The admirable stereoscopic photograph of a case of small-pox which accompanies his paper' serves well to show how much more illustrative the combined pictures are than either of them separately, the pustules standing out plump and fat upon the patient's face. Dr. Davidson specially insists on the utility of the stereoscopic method in skiagraphy, and there can be no doubt that he is right. Not only may stereoscopic skiagraphs be so arranged as to do away with the apparent distortion which is so often seen in X-ray photographs, but they give most useful information as to the depth of, say, a foreign body, which can only otherwise be obtained by careful comparison of two plates.

I Brit. Med, Jour., Dec, 3. 